\title{
CURRENT STATUS OF DENSE CERAMIC MEMBRANES FOR HYDROGEN SEPARATION
}

\author{
U. (Balu) Balachandran, T. H. Lee, S. Wang, G. Zhang and S. E. Dorris \\ Energy Technology Division, Argonne National Laboratory, Argonne, IL 60439 \\ Corresponding author: U. (Balu) Balachandran, phone 630-252-4250; fax 630-252-3604; \\ email: balu@anl.gov
}

February 2002

Paper to be presented at the $27^{\text {th }}$ International Technical Conference on Coal Utilization and Fuel Systems, Clearwater, FL, March 4-7, 2002.

*Work supported by the U.S. Department of Energy, National Energy Technoogy Laboratory, under Contract W-31-109-Eng-38. 


\title{
CURRENT STATUS OF DENSE CERAMIC MEMBRANES FOR HYDROGEN SEPARATION
}

\author{
U. (Balu) Balachandran, T. H. Lee, S. Wang, G. Zhang and S. E. Dorris \\ Energy Technology Division, Argonne National Laboratory, Argonne, IL 60439 \\ Corresponding author: U. (Balu) Balachandran, phone 630-252-4250; fax 630-252-3604; \\ email: balu@anl.gov
}

\begin{abstract}
Novel cermet (i.e., ceramic-metal composite) membranes have been developed for separating hydrogen from gas mixtures at high temperature and pressure. The hydrogen permeation rate in the temperature range of $600-900^{\circ} \mathrm{C}$ has been measured for three classes (ANL-1, -2, and -3) of cermet membranes. ANL-3 membranes provide the highest hydrogen flux $\left(16.2 \mathrm{~cm}^{3}(\mathrm{STP}) / \mathrm{min}-\mathrm{cm}^{2}\right.$ for $40 \mu \mathrm{m}$-thick ANL-3a at $900^{\circ} \mathrm{C}$ using $100 \% \mathrm{H}_{2}$ as the feed gas). The effects of membrane thickness and hydrogen partial pressure on the hydrogen flux indicate that the bulk diffusion of hydrogen is rate-limiting for ANL-3 membranes with thickness $>0.04$ mm. ANL-3b membranes were tested in simulated syngas at several temperatures for times approaching $\approx 200 \mathrm{~h}$, and no degradation in performance was observed. The lack of degradation in simulated syngas suggests that the membrane is chemically stable and may be suitable for long-term operation.
\end{abstract}

\section{INTRODUCTION}

The U.S. Department of Energy's Office of Fossil Energy sponsors a wide variety of research, development, and demonstration programs that aim to maximize the use of vast domestic fossil resources and ensure a fuel-diverse energy sector while responding to global environmental concerns. Development of cost-effective, membrane-based reactor and separation technologies is of significant interest for applications in advanced fossil-based power and fuel technologies. Because concerns over global climate change are driving nations to reduce $\mathrm{CO}_{2}$ emissions, hydrogen is considered the fuel of choice for the electric power and transportation industries. Although it is likely that renewable energy sources will ultimately be used to generate hydrogen, technologies based on fossil fuels will supply hydrogen in the interim.

The purpose of this work is to develop dense hydrogen-permeable membranes for separating hydrogen from mixed gases at commercially significant fluxes under industrially relevant operating conditions. Of particular interest is the separation of hydrogen from product streams that are generated during coal gasification (IGCC), methane partial oxidation, and watergas shift reactions. Because the membrane will separate hydrogen without using electrodes or an 
external power supply (i.e., its operation will be nongalvanic), it requires materials that exhibit suitable electronic and protonic conductivities as well as high hydrogen diffusivity and solubility. Good mechanical properties will also be necessary to withstand operating stresses. In addition, the fabricated materials must be thin and dense in order to maximize the hydrogen flux and maintain high hydrogen selectivity.

Membrane development at Argonne National Laboratory (ANL) and the National Energy Technology Laboratory (NETL) focused initially on $\mathrm{BaCe}_{0.8} \mathrm{Y}_{0.2} \mathrm{O}_{3-\delta}(\mathrm{BCY})$, because it is a mixed proton/electron conductor with a high total electrical conductivity $[1,2]$ and may therefore yield a high hydrogen flux without using electrodes or electrical circuitry. Despite its high total electrical conductivity, however, its electronic component of conductivity is insufficient to support a high nongalvanic hydrogen flux $[3,4]$. In order to increase the electronic conductivity, and thereby increase the hydrogen flux, we have developed various cermet (i.e., ceramic-metal composite) membranes, in which a metal powder is dispersed in a ceramic matrix $[5,6]$. In these cermets, the metal enhances the hydrogen permeability of the ceramic phase by increasing the electronic conductivity of the composite. If a metal with high hydrogen permeability is used, it may also provide an additional transport path for the hydrogen.

The cermet membranes in this paper are classified as ANL-1, -2, or -3, based on the hydrogen transport properties of the metal and matrix phases. ANL-1 membranes contain a metal with low hydrogen permeability that is distributed in a matrix of hydrogen-permeable BCY. ANL-2 membranes also have a BCY matrix, but contain a metal with high hydrogen permeability (i.e., a hydrogen transport metal). In ANL-3 membranes, a hydrogen transport metal is dispersed in a ceramic matrix with low hydrogen permeability, e.g., $\mathrm{Al}_{2} \mathrm{O}_{3}$ or $\mathrm{BaTiO}_{3}$. Specific membranes are identified by a number and a letter, where the number represents the type of membrane, e.g. ANL-3 membranes, and the letter indicates a particular combination of metal and matrix phases, e.g., ANL-3a is an ANL-3 membrane that contains "metal-a" in a matrix of $\mathrm{Al}_{2} \mathrm{O}_{3}$, whereas ANL-3b is another ANL-3 membrane that contains a different metal and/or a different ceramic matrix. In making general comments regarding an entire class of membranes, a number is used alone without any letter.

The first class of membranes, ANL-1, contains a metal with low hydrogen permeability in a hydrogen-permeable matrix, BCY. The hydrogen flux through ANL-1a is higher than that through monolithic BCY because the metal increases the overall electronic conductivity of the membrane. The hydrogen flux was increased with ANL-2a membranes by replacing the metal of ANL-1a with a hydrogen transport metal, i.e., a metal that has a high hydrogen permeability. Although BCY and the metal phase both contribute to the hydrogen flux through ANL-2 membranes, most of the hydrogen diffuses through the metal [7]. Because BCY contributes relatively little to the overall permeation rate of ANL-2 membranes, exhibits poor mechanical properties, and is chemically unstable under some conditions of interest, ANL-3 membranes were developed. In ANL-3 membranes, the BCY matrix of ANL-1 and -2 membranes is replaced by a ceramic with superior mechanical properties and thermodynamic stability, e.g., $\mathrm{Al}_{2} \mathrm{O}_{3}$ or $\mathrm{ZrO}_{2}$, to form a membrane that gives a higher hydrogen flux and has higher strength 
and greater chemical stability. In this paper, we discuss the state of development of the various cermet membranes (ANL-1, -2, and -3) and compare their hydrogen permeation rates.

\section{EXPERIMENTAL}

BCY powder was prepared at ANL as previously described [5]. All membranes were prepared to contain 40 vol.\% metal phase, except where otherwise noted. BCY and metal powders were mixed together to prepare powders for ANL-1a and -2a membranes. Powders for ANL-3 membranes were prepared by mixing one of two hydrogen transport metals with ceramic powders that are reported to be poor proton conductors [8]. Powders were pressed uniaxially to prepare disks ( $\approx 22 \mathrm{~mm}$ in diameter $\mathrm{x} 2 \mathrm{~mm}$ thick) for sintering.

Sintering conditions were selected on the basis of the membrane composition. ANL-1a and $-2 \mathrm{a}$ membranes were sintered for $5 \mathrm{~h}$ in $4 \% \mathrm{H}_{2} /$ balance $\mathrm{Ar}$ at $1420^{\circ} \mathrm{C}$. ANL-3a membranes were sintered for $5 \mathrm{~h}$ at $1400^{\circ} \mathrm{C}$ in $4 \% \mathrm{H}_{2} /$ balance $\mathrm{He}$, ANL-3b membranes were sintered at $1350^{\circ} \mathrm{C}$ for $12 \mathrm{~h}$ in air, and ANL-3d membranes were sintered in air for $5 \mathrm{~h}$ at $1390^{\circ} \mathrm{C}$.

To test permeation, a sintered disk was polished with 600-grit $\mathrm{SiC}$ polishing paper and then affixed to an $\mathrm{Al}_{2} \mathrm{O}_{3}$ tube that was part of the assembly shown in Fig. 1. A seal formed when the assembly was heated to $950^{\circ} \mathrm{C}$ and spring-loaded rods squeezed a gold ring between the membrane and the $\mathrm{Al}_{2} \mathrm{O}_{3}$ tube. One side of the sample was purged with $4 \% \mathrm{H}_{2}$ /balance He during sealing, while the other side was purged with $100 \mathrm{ppm}_{2} /$ balance $\mathrm{N}_{2}$. The leakage rate following this procedure was typically $<10 \%$ of the total permeation flux.

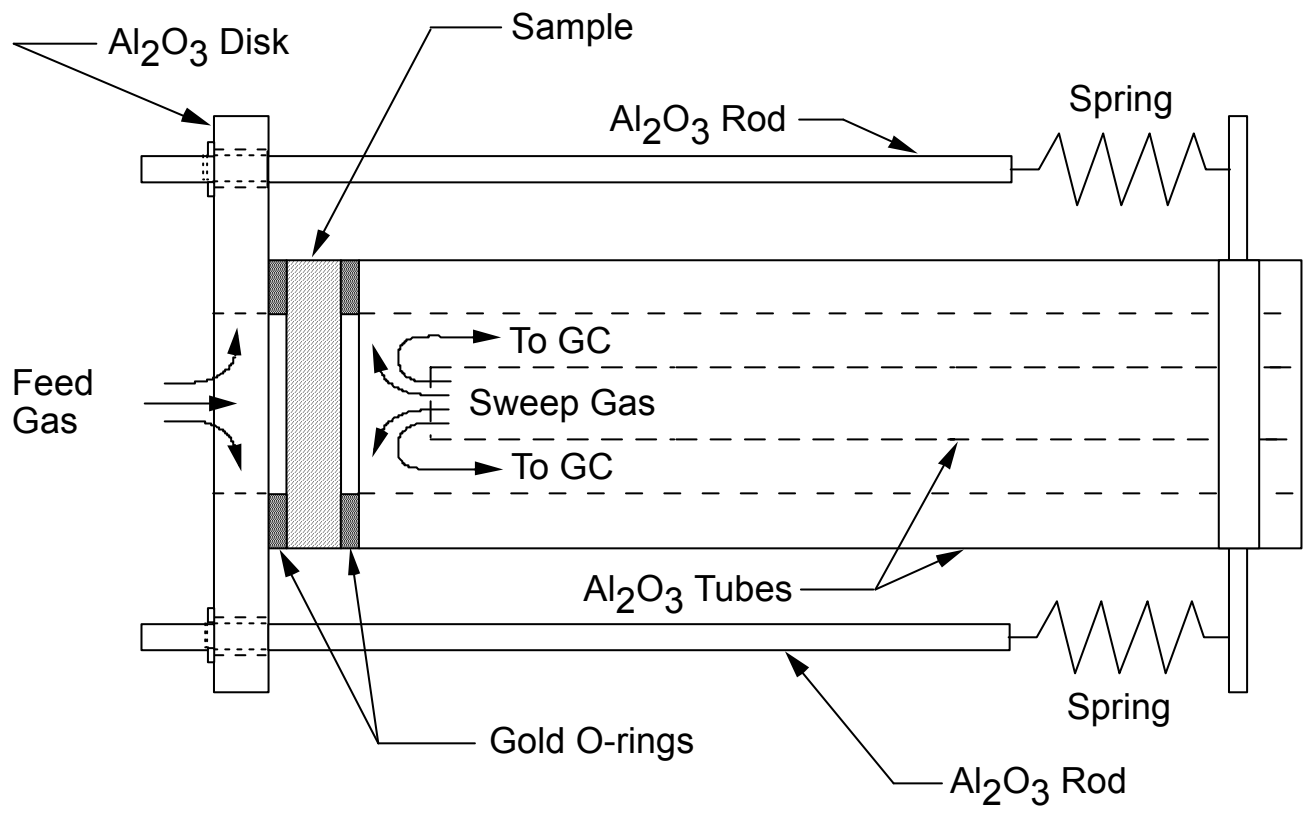

Figure 1. Experimental assembly for measuring hydrogen flux. GC = gas chromatograph. 
The flow rate of sweep gas during permeation measurements (100 ppm $\mathrm{H}_{2} /$ balance $\left.\mathrm{N}_{2}\right)$ was controlled with a mass flow controller (MKS) and was measured using a Field-Cal 570 flow calibrator from Humonics. The sweep gas was analyzed with a Hewlett-Packard 6890 gas chromatograph (GC). Feed gases included $100 \% \mathrm{H}_{2}$, simulated syngas $\left(66 \% \mathrm{H}_{2}, 33 \% \mathrm{CO}\right.$, and $1 \% \mathrm{CO}_{2}$,), and "dry" or "wet" $4 \% \mathrm{H}_{2}$ /balance He. For wet feed gas, $4 \% \mathrm{H}_{2} /$ balance He was bubbled through a water bath at room temperature to give $\approx 0.03 \mathrm{~atm} \mathrm{H}_{2} \mathrm{O}$; for the dry condition, $4 \% \mathrm{H}_{2} /$ balance He was introduced directly into the furnace from the gas cylinder.

\section{RESULTS}

The hydrogen permeation rates for ANL-1a, $-2 a$, and $-3 b$ are compared in Fig. 2 for a feed gas of $4 \% \mathrm{H}_{2} /$ balance He. In order to directly compare the permeation properties of the membranes, their thicknesses were normalized to that for ANL-1a, i.e., $0.50 \mathrm{~mm}$. The original thickness of each membrane is shown in the inset for Fig. 2. Among these membranes, ANL-3b

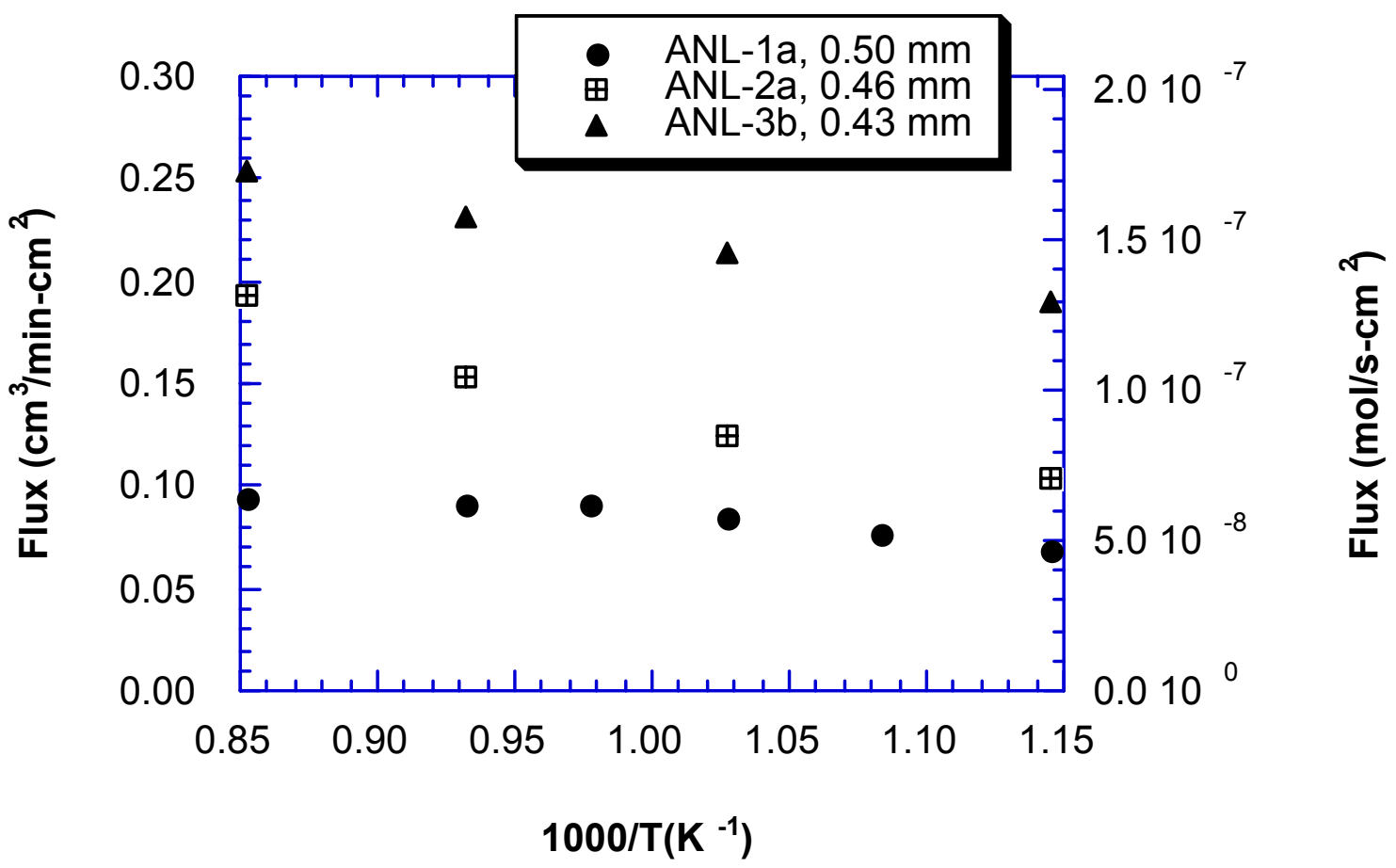

Figure 2. Hydrogen permeation rates through ANL-1a, $-2 \mathrm{a}$, and $-3 \mathrm{~b}$ when wet $4 \% \mathrm{H}_{2} /$ balance He was feed gas. Thicknesses are normalized to $0.5 \mathrm{~mm}$; original thickness of each membrane shown on inset. 
exhibited the highest permeation rate, which was approximately three times higher than that of ANL-1a over the whole temperature range. When compared with ANL-2a, the permeation rate for ANL-3b was $\approx 35 \%$ higher at $900^{\circ} \mathrm{C}$ and $\approx 80 \%$ higher at $600^{\circ} \mathrm{C}$. ANL-3b gave the highest permeation rate because its metal phase had the highest hydrogen permeability of the various metals tested to date.

Figure 3 shows the temperature and thickness dependence of the hydrogen flux through ANL-3b when wet $100 \% \mathrm{H}_{2}$ was used as the feed gas. The permeation flux for the $0.1-\mathrm{mm}$-thick membrane is shown only at $900^{\circ} \mathrm{C}$, because the leakage was high at lower temperatures. With a feed gas of either $100 \% \mathrm{H}_{2}$ (Fig. 3) or $4 \% \mathrm{H}_{2}$ /balance He (Fig. 2), the hydrogen permeation rate increased with temperature and was proportional to the inverse of membrane thickness over the whole temperature range. The inverse dependence of flux on thickness indicates that the bulk diffusion of hydrogen is rate-limiting for thickness $>0.1 \mathrm{~mm}$. Figure 4 shows the temperature

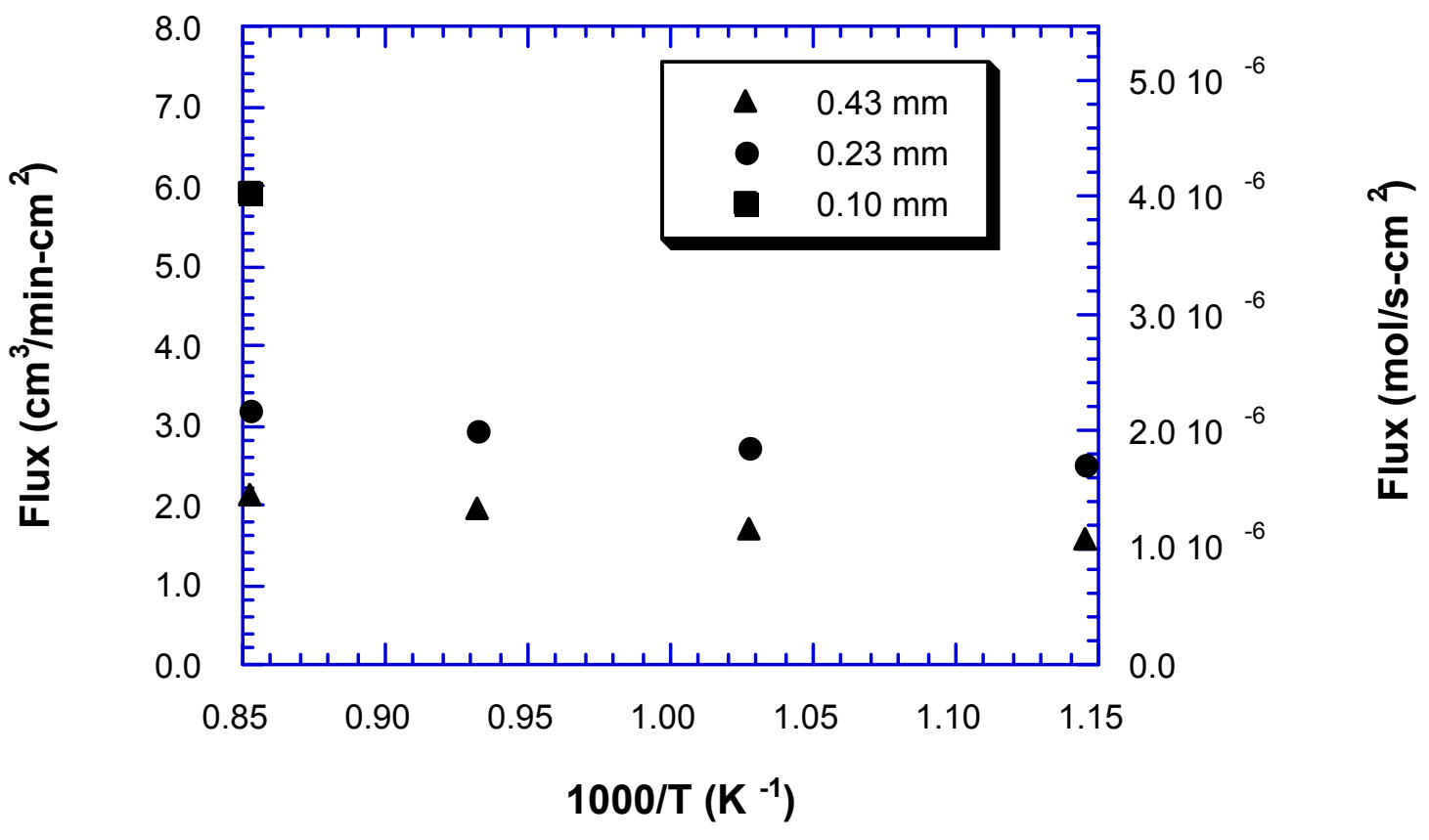

Figure 3. Hydrogen permeation rate through 0.10-, 0.23- and 0.43-mm-thick ANL-3b when the feed gas was wet $100 \% \mathrm{H}_{2}$. 


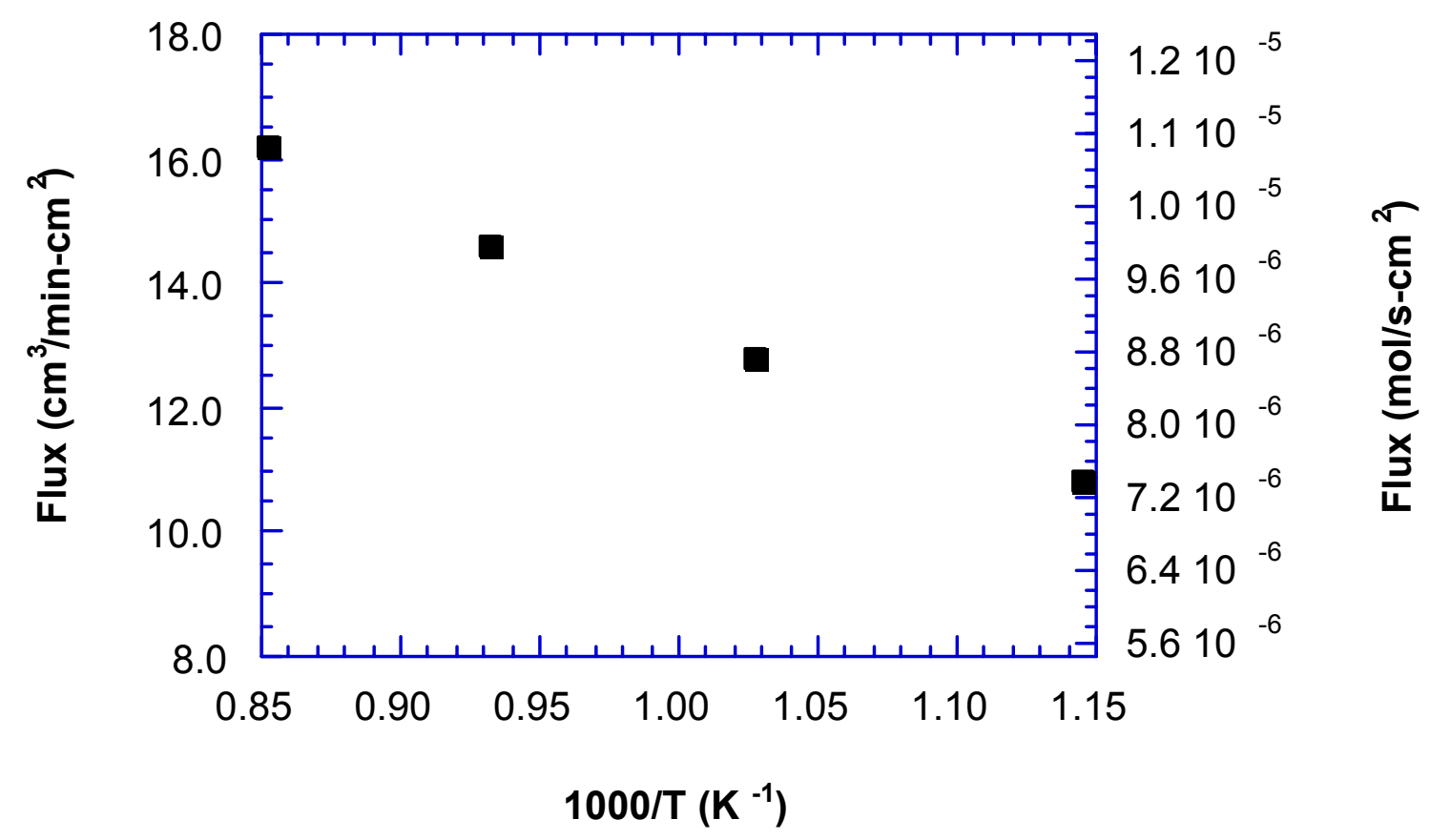

Figure 4. The hydrogen flux through an ANL-3a membrane (thickness $=0.04 \mathrm{~mm}$ ) that contained 50 vol. $\%$ of a hydrogen transport metal. Feed gas was $100 \% \mathrm{H}_{2}$.

dependence of hydrogen flux through an ANL-3a membrane (thickness $=0.04 \mathrm{~mm}$ ) that contained $50 \mathrm{vol} . \%$ of a hydrogen transport metal. Although it (Fig. 4) contains a different composition and concentration of metal than the ANL-3b membranes (Fig. 3), the significantly higher flux for the ANL-3a membrane can be attributed primarily to its reduced thickness. This indicates that the bulk diffusion of hydrogen is rate-limiting down to this thickness, and suggests that reducing membrane thickness further may increase the permeation flux.

The effect of hydrogen partial pressure on flux is shown in Fig. 5 for an ANL-3b membrane (thickness $=0.23 \mathrm{~mm}$ ) at 800 and $900^{\circ} \mathrm{C}$. The hydrogen flux (Fig. 5) is plotted as a function of the difference in square root of hydrogen partial pressure for the feed and sweep sides of the membrane. At both temperatures, the flux varies linearly with the difference in square root of hydrogen partial pressure. Such a dependence on hydrogen partial pressure is characteristic of bulk-limited hydrogen diffusion through metals [9], and confirms that in this thickness range, the 


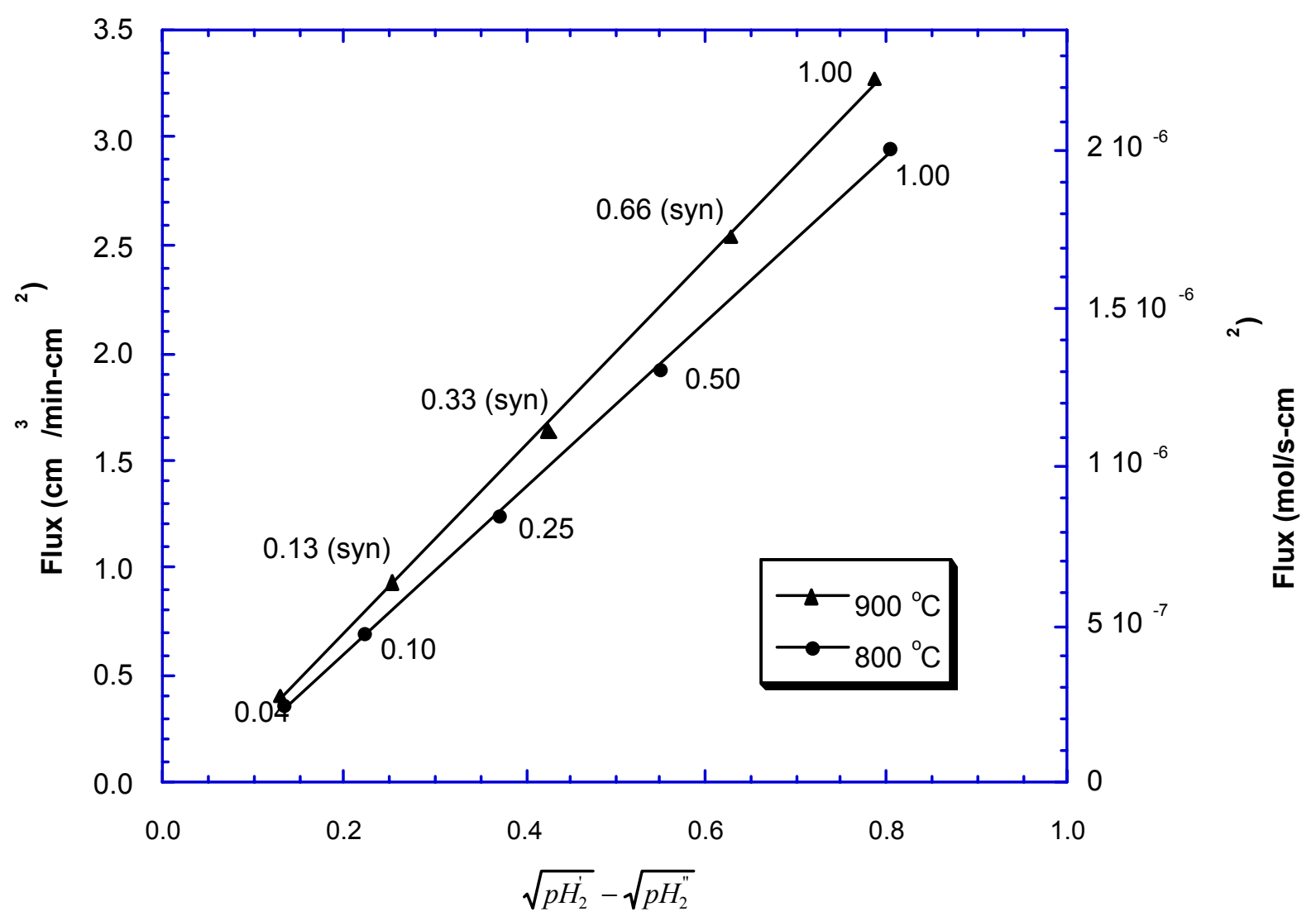

Figure 5. Dependence of hydrogen permeation rate on partial pressure of hydrogen $\left(\mathrm{pH}_{2}\right)$ for ANL-3b (thickness $=0.23 \mathrm{~mm}$ ). $\mathrm{pH}_{2}{ }^{\prime}=\mathrm{pH}_{2}$ of feed gas; $\mathrm{pH}_{2}{ }^{\prime \prime}=\mathrm{pH}_{2}$ of sweep gas; $\mathrm{pH}_{2}$ of feed gas indicated on figure; (syn) $=$ gas mixtures made with simulated syngas.

bulk diffusion of hydrogen through the metal phase dominates the hydrogen flux through ANL-3b membranes. At some lesser thickness, however, interfacial reactions may become rate-limiting.

The chemical stability of ANL-3b in simulated syngas $\left(66 \% \mathrm{H}_{2}, 33 \% \mathrm{CO}\right.$, and $\left.1 \% \mathrm{CO}_{2}\right)$ was tested by measuring its hydrogen flux at several temperatures for times up to $190 \mathrm{~h}$. The results obtained from a 0.43 -mm-thick membrane are shown in Fig. 6. Feed gas of $4 \% \mathrm{H}_{2} /$ balance $\mathrm{He}$ was flowed before and after exposure to syngas at each temperature in order to measure the leakage rate of hydrogen by measuring the helium concentration in the sweep gas. No helium leakage was measured at any of the temperatures. Figure 6 shows no noticeable decrease in flux during up to $190 \mathrm{~h}$ of operation at each temperature. Likewise, similar tests with 0.23 -mm-thick ANL-3b showed no decrease in the hydrogen flux during $120 \mathrm{~h}$ of exposure to syngas at $900^{\circ} \mathrm{C}$. 


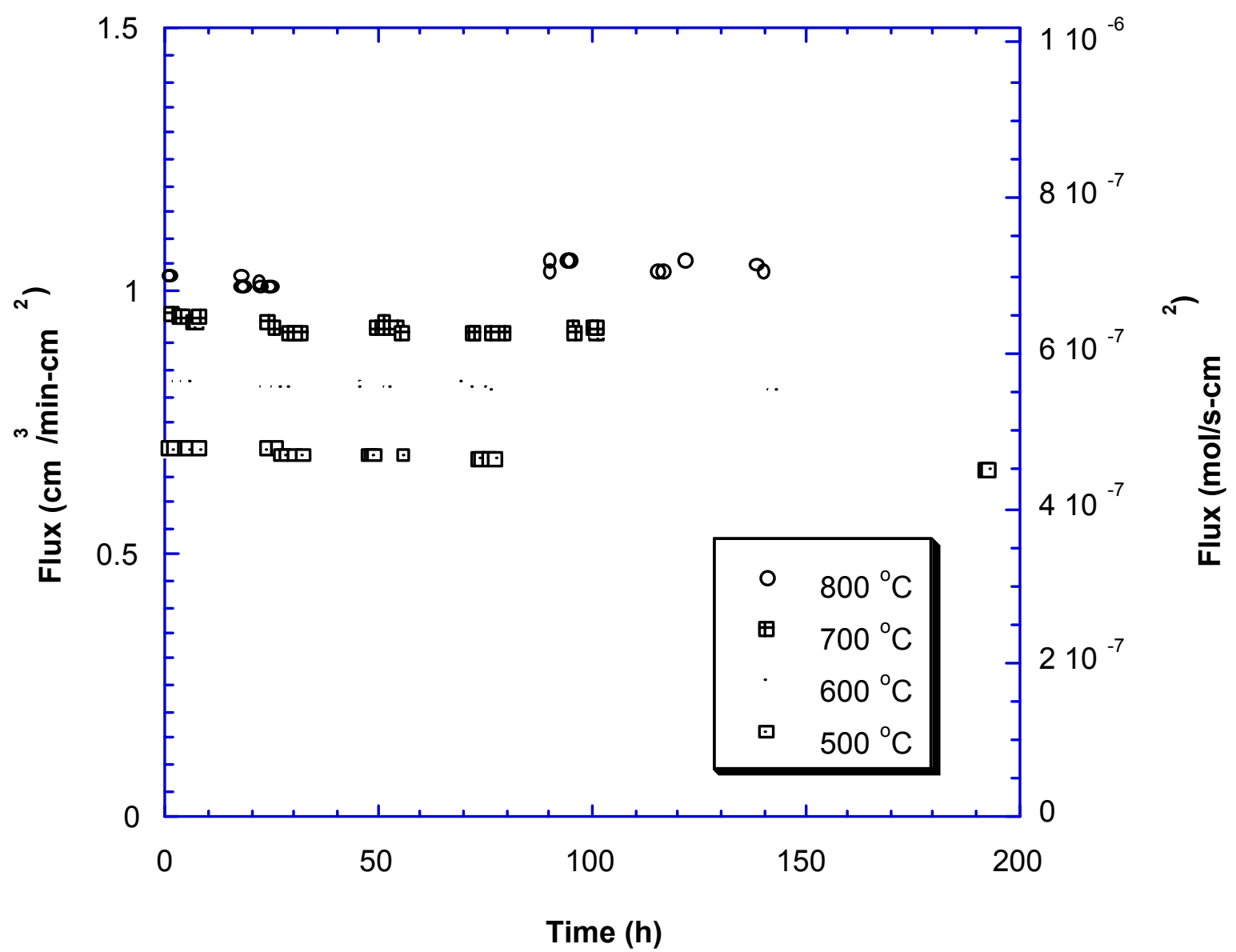

Figure 6. Hydrogen permeation rate through ANL-3b (0.43-mm-thick) vs. time in simulated syngas $\left(66 \% \mathrm{H}_{2}, 33 \% \mathrm{CO}\right.$, and $\left.1 \% \mathrm{CO}_{2}\right)$ at various temperatures.

$\mathrm{BaTiO}_{3}$ is a convenient matrix for ANL-3b membranes, because its sintering temperature is relatively low when compared to that of $\mathrm{Al}_{2} \mathrm{O}_{3}$; on the other hand, $\mathrm{Al}_{2} \mathrm{O}_{3}$ is stronger and exhibits better structural reliability. To improve the mechanical properties of thin ANL-3 membranes, ANL-3d membranes were developed in which the hydrogen transport metal of ANL-3b was dispersed in a matrix of $\mathrm{Al}_{2} \mathrm{O}_{3}$ rather than $\mathrm{BaTiO}_{3}$. Because the melting point of the metal is lower than the sintering temperature of $\mathrm{Al}_{2} \mathrm{O}_{3}$, however, dense membranes could be obtained only when a sintering aid was added. Handling of the membrane during preparation for permeation tests demonstrated qualitatively that ANL-3d was significantly stronger and harder than ANL-3b. Figure 7 shows that the permeation properties of ANL-3d are nearly the same as those of ANL-3b. 


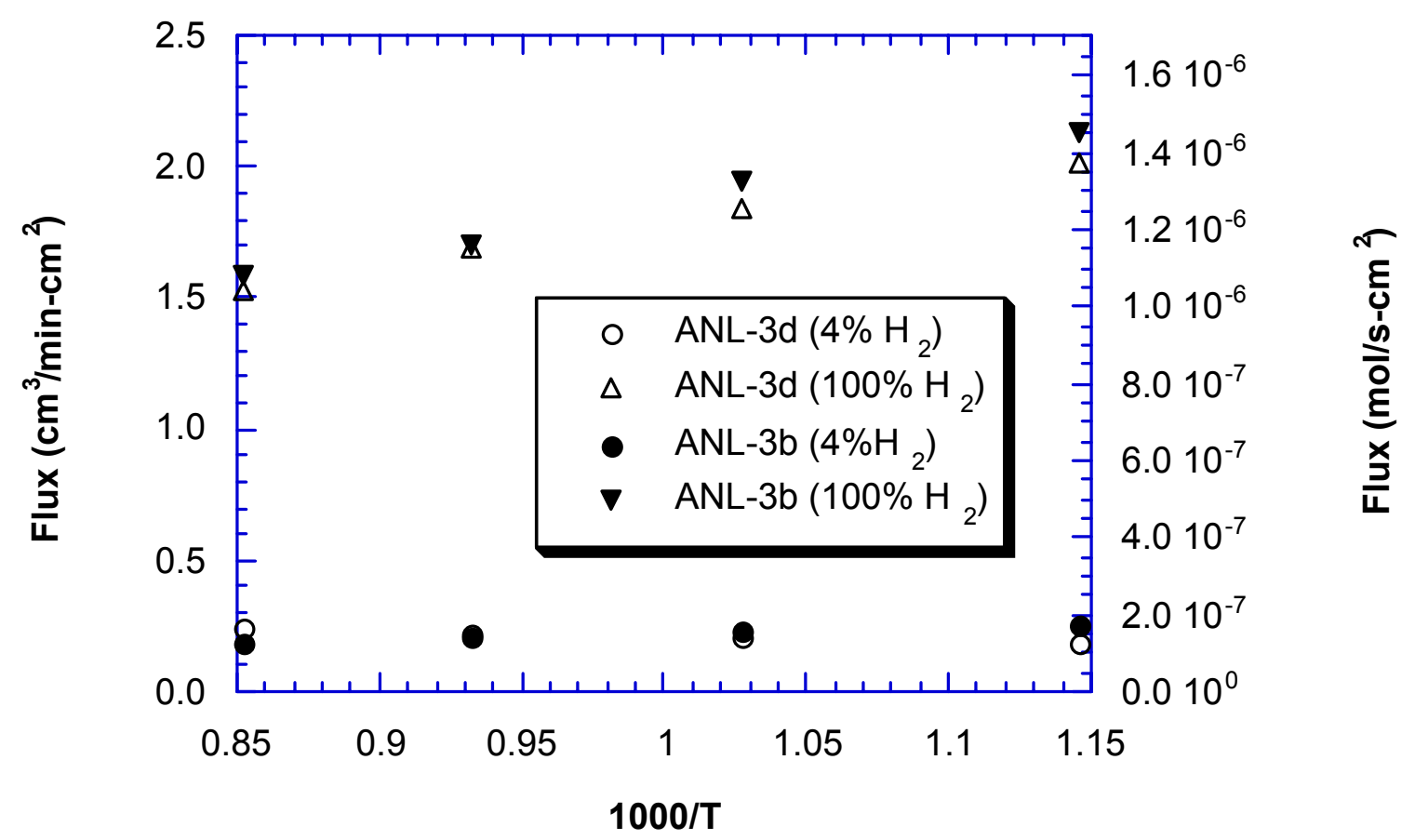

Figure 7. Hydrogen permeation rates of ANL-3b and -3d membranes when feed gas was $4 \% \mathrm{H}_{2}$ and $100 \% \mathrm{H}_{2}$. The membrane thickness of ANL-3d $(0.53 \mathrm{~mm})$ was normalized to that for ANL$3 \mathrm{~b}(0.43 \mathrm{~mm})$ to allow direct comparison of permeation properties.

The thickness of ANL-3d, $0.53 \mathrm{~mm}$, was normalized to the thickness for ANL-3b, $0.43 \mathrm{~mm}$, to directly compare their permeation properties. The similarity in permeation rates indicates that the sintering aid did not degrade the properties of the hydrogen transport metal.

Figure 8 shows that the $\mathrm{Al}_{2} \mathrm{O}_{3}$ matrix of ANL-3d is chemically more stable than the $\mathrm{BCY}$ matrix of ANL-2a in an environment that contains high concentrations of $\mathrm{CO}_{2}$. The permeation rate through the two membranes is shown in Fig. 8 as a function of time at $900^{\circ} \mathrm{C}$ in dry and wet syngas of composition $2.0 \% \mathrm{CH}_{4}, 19.6 \% \mathrm{H}_{2}, 19.6 \% \mathrm{CO}$, and $58.8 \% \mathrm{CO}_{2}$ (mol.\%). The permeation rate through ANL-2a decreased dramatically after only several minutes, whereas the hydrogen flux through ANL-3d was stable for $>3 \mathrm{~h}$. Examination of the ANL-2a surface by scanning electron microscopy after the permeation measurements showed that the BCY matrix had decomposed to form $\mathrm{BaCO}_{3}$ and other phases. These results show that a chemically stable matrix such as $\mathrm{Al}_{2} \mathrm{O}_{3}$ or $\mathrm{ZrO}_{2}$ will be required for application of the membrane in atmospheres with high $\mathrm{CO}_{2}$ concentrations. 


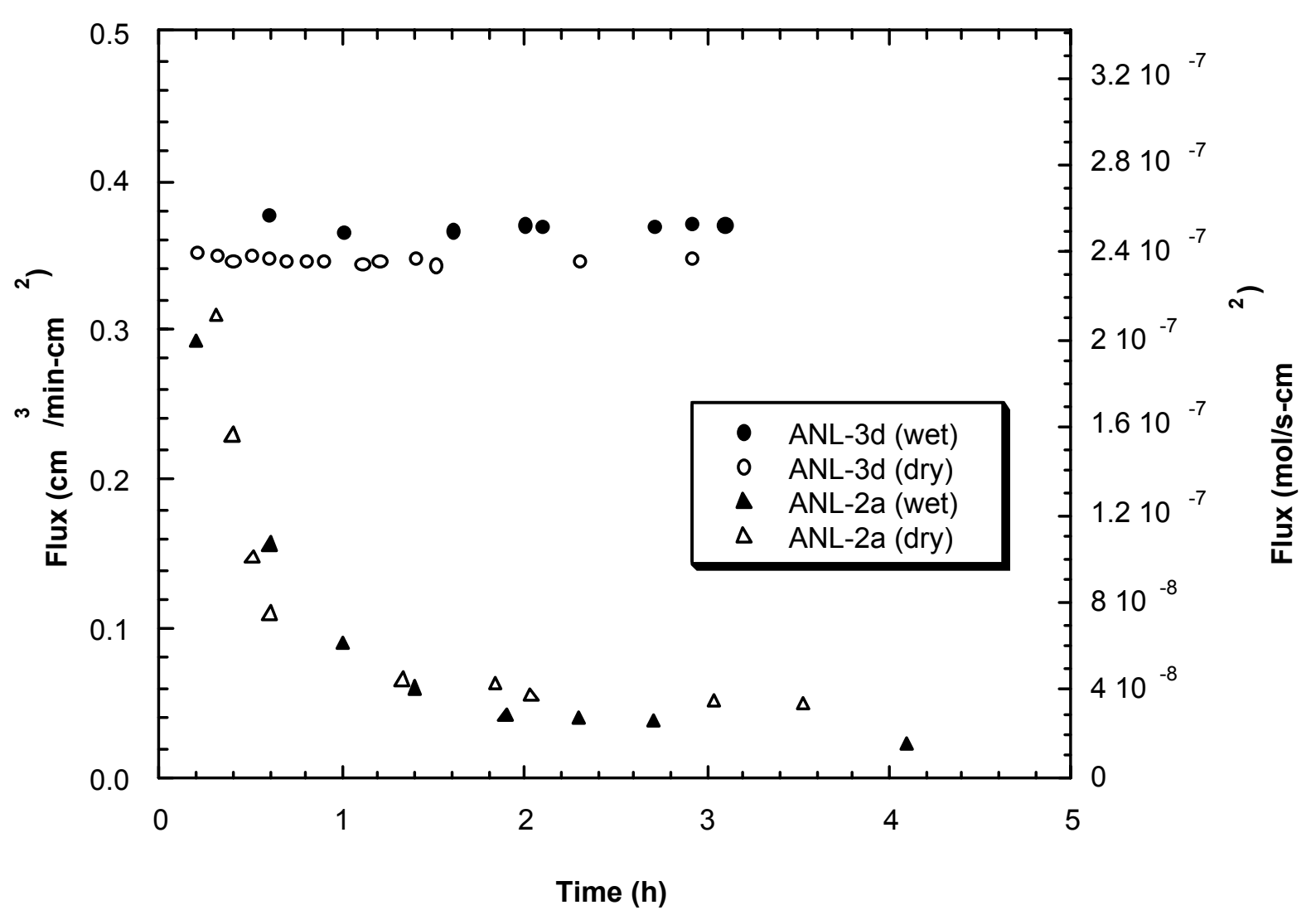

Figure 8. Permeation rate through $\mathrm{Al}_{2} \mathrm{O}_{3}$-based ANL-3d and BCY-based ANL-2a in a feed gas containing $2.0 \% \mathrm{CH}_{4}, 19.6 \% \mathrm{H}_{2}, 19.6 \% \mathrm{CO}$, and $58.8 \% \mathrm{CO}_{2}$ (mol.\%). Thickness of ANL-3d membrane was $0.53 \mathrm{~mm}$; thickness of ANL-2a, $0.43 \mathrm{~mm}$.

\section{CONCLUSIONS}

We have developed cermet membranes that nongalvanically separate hydrogen from gas mixtures. The highest measured hydrogen flux was $16.2 \mathrm{~cm}^{3}(\mathrm{STP}) / \mathrm{min}-\mathrm{cm}^{2}$ for an ANL-3a membrane at $900^{\circ} \mathrm{C}$. For ANL-3 membranes with thickness of $0.04-0.5 \mathrm{~mm}$, permeation rate is limited by the bulk diffusion of hydrogen through the metal phase. The effect of hydrogen partial pressure on permeation rate confirmed this conclusion and suggested that higher permeation rates may be obtained by decreasing the membrane thickness. Permeation rate in a syngas atmosphere for times up to $190 \mathrm{~h}$ showed no degradation in performance, which indicates that ANL-3 membranes may be suitable for long-term, practical hydrogen separation. 


\section{ACKNOWLEDGMENTS}

This work is supported by the U.S. Department of Energy, National Energy Technology Laboratory, under Contract W-31-109-Eng-38.

\section{REFERENCES}

[1]. H. Iwahara, T. Yajima, and H. Uchida, Solid State Ionics, 70/71, 267 (1994).

[2]. H. Iwahara, Solid State Ionics, 77, 289 (1995).

[3]. J. Guan, S. E. Dorris, U. Balachandran, and M. Liu, Solid State Ionics, 100, 45 (1997).

[4]. J. Guan, S. E. Dorris, U. Balachandran, and M. Liu, J. Electrochem. Soc., 145, 1780 (1998).

[5]. J. Guan, S. E. Dorris, U. Balachandran, and M. Liu, Ceram. Trans., 92, 1 (1998).

[6]. U. Balachandran, T. H. Lee and S. E. Dorris, in Proc. 16th Annual International Pittsburgh Coal Conf., Pittsburgh, PA, Oct. 11-15, 1999, Pittsburg Coal Conf. Pittsburgh, PA.[1]. S. Uemiya, Separation and Purification Methods, 28(1), 51 (1999).

[7]. U. Balachandran, T. H. Lee, G. Zhang, S. E. Dorris, K. S. Rothenberger, B. H. Howard, B. Morreale, A. V. Cugini, R. V. Siriwardane, J. A. Poston Jr., and E. P. Fisher, in Proc. 26th Intl. Technical Conf. on Coal Utilization and Fuel Systems, Clearwater, FL, Mar. 5-8, 2001, Coal Technical Association, Gaithersburg, MD. pp. 751-761.

[8]. K.-D. Kreuer, Chem. Mater., 8, 610 (1996).

[9]. R. E. Buxbaum and T. L. Marker, J. Membr. Sci., 85, 29 (1993). 